\title{
CHILDREN WITH DISABILITIES COMMUNITY ASSESSMENT - AUTISM
}

\author{
Sarah Boomer, Libby Blore, Sian Louden, Nicola McQuillan, \\ Maddie Nash, Ailing Pang, Sarah Roy and Laurie Mahoney
}

\section{INTRODUCTION}

This group of seven third-year Bachelor of Nursing learners at Otago Polytechnic undertook a community development project for their Primary Health Practice in 2020 in Dunedin, New Zealand. The learners applied the Community Health Assessment Sustainable Education (CHASE) model (Ross, Crawley \& Mahoney, 2017) to complete a community profile of children with disabilities. The model allows nursing students to view primary health nursing from a sustainable and population-based approach, where health needs in communities are identified by a process of profiling the community and applying a needs analysis to identify health needs that the students then research to develop a sustainable approach or resource to reduce the need within the community.

Over the period of 2016-19, nursing students profiled the lower South Island areas of Otago and Southland, concentrating on rural/semi-rural populations. In 2019, it was noted that professionals working in the city areas (primarily Dunedin city) were somewhat reluctant to engage with students. With this in mind, and with the awareness that the lecturers did not want to 'over research' populations, it was decided that population aggregates would be researched by the majority of third-year learners in 2020. Individual groups of up to nine learners researched aggregates including children with disabilities concentrating on Autism, adults living with Multiple Sclerosis (MS), Cerebral Vascular Accidents (commonly known as strokes), Diabetes, and Chronic Obstructive Pulmonary Disorder (COPD). This is the first report from this group of learners and focuses on children living with disabilities, particularly Autism.

The lecturing staff identified the broad topic of people with disabilities and chronic health conditions as the core topics for learners to research. After brain-storming the wider topic, the learners then decided to concentrate on children with disabilities in New Zealand and then further narrowed their project down to focus on the needs of children with Autism Spectrum Disorder (ASD).

The CHASE model (Ross et al., 2017) builds on the Community-as-Partner model (Anderson \& McFarlane, 2008). The leaners report included in-depth information on all eight subsystems, however the community profile for this report is limited to the politics and education, and then explores Autism in greater depth. 


\section{PART I: COMMUNITY}

According to the 2013 New Zealand Statistics it is noted that 24 percent of the population have some form of a disability with many people identifying as having more than one impairment or condition and 53 percent of those with disabilities in New Zealand having multiple disabilities (Statistics New Zealand, 2013).

The three main types of disabilities are physical, intellectual, and mental health, with intellectual disabilities being the most common (Statistics New Zealand, 2019). The main impairments caused by disabilities varies between children and adults with the main impairments experienced by New Zealand adults are physical (18 percent) compared to I percent for children. The most common impairment in children is psychological/psychiatric (4 percent), although 'other' includes learning, developmental delay, and speech is 7 percent (Statistics New Zealand, 2013).

Although disabilities affect everyone, regardless of socioeconomic status, ethnicity or gender, there are still disparities and inequities regarding the amount of people that are affected. Māori have disproportionately higher numbers of disabilities within their population. The 2013 Disability Survey found that Māori are more likely to be disabled (26 percent) than non-Māori (24 percent). The disparity is even higher among children as Māori children have a disability rate of 15 percent, whereas non-Māori children have a disability rate of 9 percent (Statistics New Zealand, 2013).

The biggest struggle for children with a disability in New Zealand is social interaction with peers in a variety of social settings. According to Statistics New Zealand (2019), children with disabilities are far less likely to participate in social events, such as sports teams. A key indicator in recognizing the first signs of a child developing an intellectual disability is the child's inability to interact with their peers (Ministries of Health and Education, 20I6). Intellectual disabilities are often marked by developmental delays, which can be identified early by the child's parents/caregiver, early childhood educators, Plunket/Well Child nurses and the child's general practitioner (GP) (Ministries of Health and Education, 2016, Plunket New Zealand, 2020).

Along with difficulty in social interaction, communication with a child who has an intellectual disability can be tough, particularly if they are non-verbal. At school, the all too common noise and busy classrooms, effect many children's ability to concentrate on their learning, with sensory overload being an additional challenge for many children with disabilities. Therefore, managing the environment for the child is important (Altogether Autism, 2020). Communicating with the child's school and managing the environment around the family home is key to the prevention of sensory overload (Ministry of Education, 2020). Loud noises and new environments can be overwhelming for children with intellectual disabilities and this is important to recognise as the child may not be able to express that sensory overload is what they are experiencing (Ministry of Education, 2020). The use of simple toys can help with calming children down, such as stress balls, a fun timer, and the use of different textures the child can touch (Altogether Autism, 2020).

Children with physical disabilities can also struggle to communicate with their peers, particularly in a busy social setting (Ministries of Health and Education, 2016). For children with disabilities, this can be even more challenging as they can be seen as different by their peers, and children with Autism, the lack of social awareness about the condition makes it harder to form connections (Lindsey \& McPherson, 20II).

Statistics from the New Zealand Disability Survey (2013) identified the following:

- 24 percent of children with disabilities have an unmet need for help with their schoolwork in class.

- 13 percent have an unmet need for special equipment to aid their learning.

- 28 percent have an unmet need for adapted classroom materials.

- 20 percent of children with a disability have had their schooling interrupted for a long period of time.

- 19 percent have difficulty attending school for the whole day (Statistics New Zealand, 2013). 
These statistics show a huge disparity in schooling among children with disabilities. Not only do many of these children face disadvantages due to impairments, bullying and discrimination is prevalent for these children as they are at higher risk than their more abled peers (Lindsay \& McPherson, 20II). This contributes to a plethora of issues, making it difficult for children with disabilities to remain in mainstream schooling.

\section{Politics and Government}

The Ministry of Health (2015) states in the 2013 New Zealand Disability Survey that 121,000 children in New Zealand identify as having a disability. The New Zealand Government, via the Ministries of Health and Education have strategies and action plans in place to assist and support children with disabilities.

The Disability Strategy 2016-2026 has the vision to ensure disabled people receive the same opportunities as non-disabled people to achieve their goals. This strategy ensures disabled people are treated fairly, that they have access to a better quality of life, can make their own decisions, and feel a part of the community. Figure I shows the eight streams of the Disability Strategy 2016-26 (Office for Disability Issues, 2019).

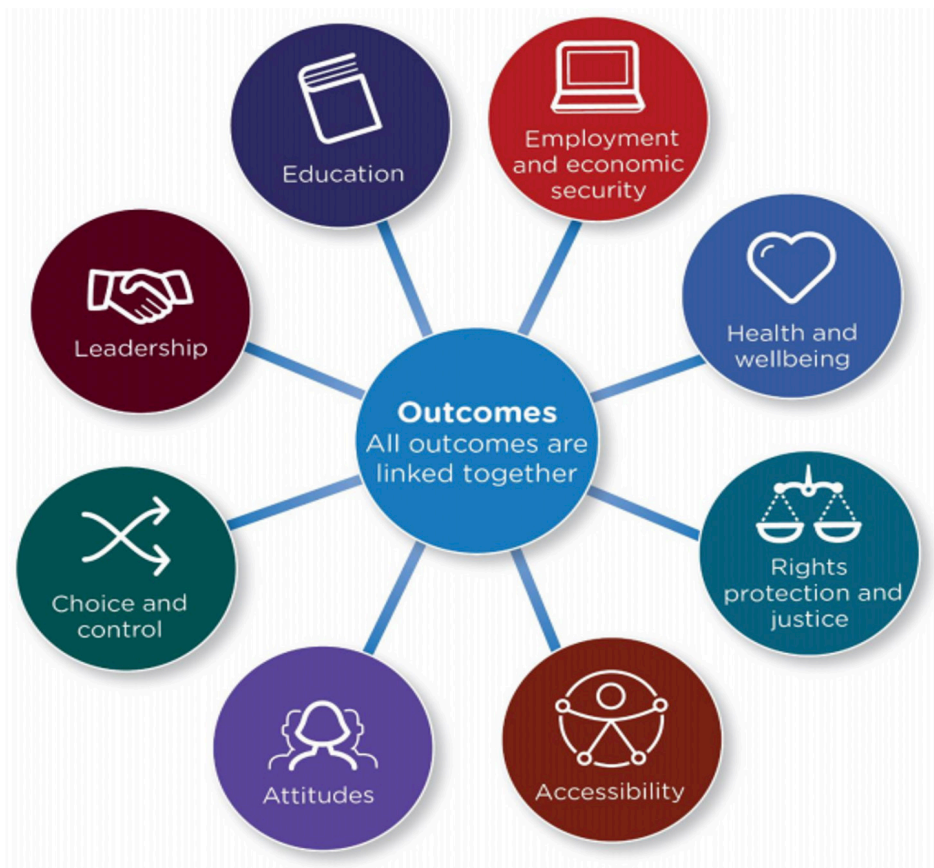

Figure I. New Zealand Disability Strategy 2016 to 2026. Source: Office for Disability Services (2016),

(published with permission).

The Māori Disability Action Plan - Whaia Te Ao Mārama 2018-2022 is a culturally anchored approach to support Māori with disabilities. The aim of this action plan is to establish priority areas of action and enable Māori with disabilities and their whanau to attain a good quality of life that meets their aspirations (Ministry of Health, 20l8). Whaia Te Ao Mārama was developed in partnership with the Māori Disability stakeholders, with oversight and endorsement of Te Ao Mārama.

The Māori Disability Action Plan provides advice to the Ministry of Health on issues that affect Mãori with disabilities (tāngata whaikaha Māori) as well as the effectiveness of the plan's implementation. The group includes tāngata 
whaikaha Māori, whānau of tāngata whaikaha Māori, Māori that work within the disability sector and experts on Māori cultural matters (Ministry of Health, 20I8). The vision of Whaia Te Ao Marama: "Tāngata whaikaha pursue a good life with support" can be seen in Figure 2 (Ministry of Health, 2018, p.3).

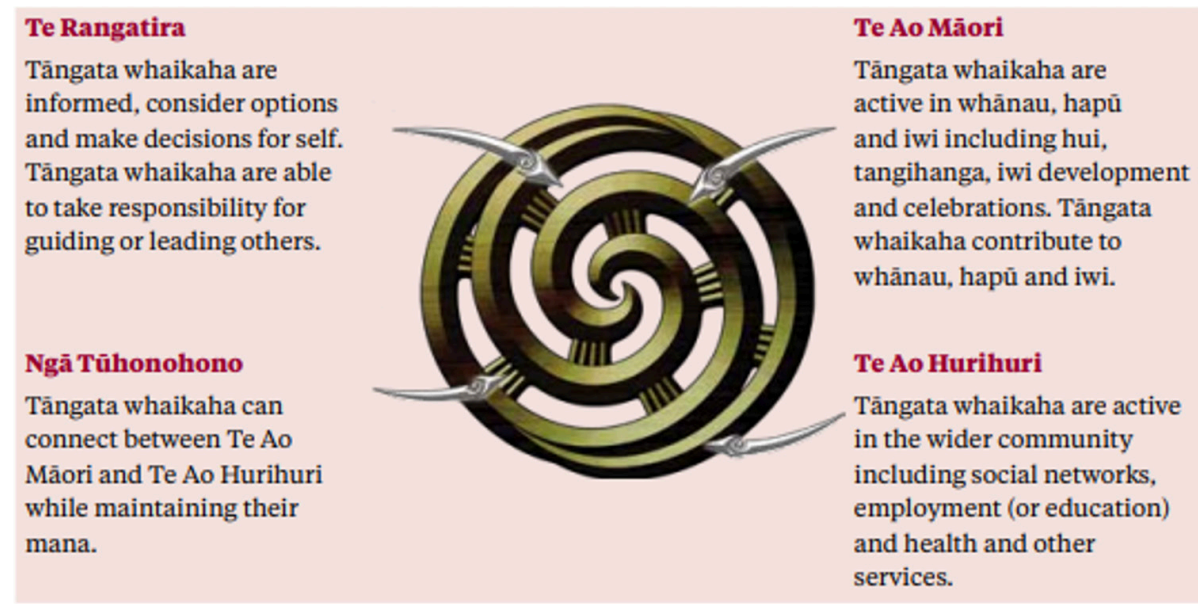

Figure 2. The Māori Disability Action Plan, 2018 to 2022. Source: Ministry of Health (2018).

The image displayed in Figure 3 signifies a torino (double spiral), symbolizing "the world of light that was created with the separation of Ranginui and Papatūānuku" (Ministry of Health, 20I8, p.3). Each element represents an aspect of Whaia Te Ao Mārama and the actions and priorities in this plan are to support Māori with disabilities on this pathway (Ministry of Health, 2018).

\section{PART 2: CHILDREN WITH AUTISM}

Autism Spectrum Disorder (ASD) is a lifelong neurodevelopmental condition that affects how people perceive the world, how they think and behave, as well as how they communicate and interact with others (Ministries of Health and Education, 2016). ASD is not an illness or disease and cannot be 'cured', rather Autism is a spectrum condition, meaning that some people are affected more than others. For example, some autistic people do not use spoken language, while others have excellent spoken language skills but may find it difficult to understand what other people are attempting to communicate (Very Well Health, 2019).

While all autistic people share some common differences in the way they hear, feel and see the world, they all have different strengths, abilities and challenges which affect their lives in different ways, at different ages and in different environments. This is because Autism is a spectrum, and people diagnosed with this condition present with various traits and behaviours. Because of this no two people with ASD will be the same (Altogether Autism, 2020).

"On the spectrum" usually refers to a specific set of behavioral and developmental problems and the challenges associated with. A diagnosis of ASD means that a child's communication, social, and play skills are affected in some way. Experts use different terms to describe ASD. These include:

- Pervasive Developmental Disorder (PDD).

- Pervasive Developmental Disorder-not otherwise specified (PDD-NOS).

- Asperger Syndrome.

- High functioning Autism. 
Classic Autism, or Autistic Disorder, is the most severe of the ASD disorders. Milder variants are known as what used to be referred to as Asperger's Syndrome, sometimes known as high-functioning autism, and PDD-NOS, or atypical autism. According to the Autism Spectrum Resource Center, only 20\% of people on the Spectrum have 'classic autism'. The overwhelming majority fall somewhere on the milder range of the Spectrum (Altogether Autism, 2020). Recently however, Asperger's Syndrome has been removed from the diagnostic manual, leaving only one general category of Autism (Autism NZ advocate, personal communication, February II, 2020).

It is important to note, however, that there is no official diagnosis of 'high' or 'low' functioning Autism, instead they are terms used to help determine and explain one's level of functioning. People with high functioning Autism do not have an intellectual disability, however they struggle with social interaction, social isolation as well as employment. People with low functioning Autism are those who are often non-verbal, struggle with daily activity and may require extra care and attention (Very Well Health, 2019).

Some people with Autism may also have cognitive difficulties while others have mental health issues, most commonly anxiety, depression and Attention Deficit Hyperactivity Disorder (ADHD). The differences between people in terms of their Autistic traits and the impact of other conditions means that people need different levels of support (Ministries of Health and Education, 20II). With the right support, all autistic people can lead fulfilling lives and live as part of their community (Altogether Autism, 2020).

\section{Identifying Autism}

To determine whether a child has Autism, a related ASD, or a different developmental condition, health professionals assess how the child pattern of behaviour including how they socialise, communicate and behave. The team of specialists involved in diagnosing a child may include:

- Child psychologists

- Child psychiatrists

- Speech pathologists

- Developmental pediatricians

- Pediatric neurologists

- Audiologists

- $\quad$ Physical therapists

- Special education teachers.

Determining where a child falls "on the spectrum" is not a brief process. There is no single medical test that can definitively diagnose it; instead, to accurately pinpoint a child's problem, multiple evaluations and tests are necessary (Milestones Day School and Transitions Programme, 2020).

\section{Diagnostic Process}

Before the diagnostic process, according to Autism.org.nz, parents may wish to complete an online screening test, such as the test: ASDetect. These tools do not provide a formal definitive diagnosis, but they can help guide a parent's decision as to whether or not they want to pursue their concerns.

If ASD is suspected, the child and caregiver should meet with their family general practitioner (GP) to discuss concerns regarding the child's behaviour and suspected symptoms. The GP will refer children onto a developmental paediatrician for an assessment of ASD. Following this the child will be referred to a child psychiatrist, clinical psychologist, or perhaps a team of clinicians that could potentially include a speech language therapist or occupational therapist. The diagnosis provided may confirm ASD or suggest another cause for the behaviour observed. This process is often very time consuming, taking many months or years to form a definitive diagnosis. 


\section{Diagnosis Criteria}

The Diagnostic and Statistical manual of Mental Disorders (5th edition), or 'DSM-5', produced by the American Psychiatric Association is used to diagnose ASD.

The DSM-5 defines ASD as "persistent difficulties with social communication and social interaction" and "restricted and repetitive patterns of behaviours, activities or interests" (this includes sensory behaviour), present since early childhood, to the extent that these "limit and impair everyday functioning (National Autistic Society, 2016). The DSM-5 lists the signs and symptoms of ASD and states how many of these symptoms must be present to confirm a diagnosis of ASD. Professionals diagnose ASD on the basis of difficulties in a minimum of two areas: social communication, and restricted, repetitive behaviour or interests.

To be diagnosed with ASD, a child must have difficulties in two areas and have had symptoms from early childhood, although many if these are not picked up until later in childhood. An ASD diagnosis includes a severity ranking, which is used to show how much support a child requires:

- Level I: needs support

- $\quad$ Level 2: needs substantial support

- Level 3: needs very substantial support (National Autistic Society, 2016).

\section{Length of Diagnosis}

The duration of time a diagnostic assessment takes depends on a number of factors, including the age of the child, their symptom severity and the type of assessment. Studies show that a valid clinical diagnosis can often be made by the time the child is aged 2-3 years but only in the more severe forms of Autism e.g. non-communicative. However, diagnosis is more difficult in young children who are more able, and in those with general developmental delay (Altogether Autism, 2020). Successful identification of ASD in young children and the effectiveness of early intervention programmes are dependent on the ability of primary care providers to monitor children's development and initiate referrals in a timely manner.

According to Zuckerman, Lindly and Chavez (2017), the "mean age of diagnosis was 4.4 years, and mean diagnostic delay was 2.2 years" (p. 33). A diagnostic assessment may take as little as one hour for a young child presenting with severe symptoms. However, children with less severe symptoms are more difficult to diagnose, with some people not being diagnosed until their early teens (Altogether Autism, 2020). Teachers, Well Child nurses, GPs and other members of the primary health care team are therefore central to early identification.

Additionally, throughout New Zealand there is no consistent referral and assessment pathway for children with ASD (or indeed children with other developmental problems). Multiple potential referral points exist, such as Child Development Services or Ministry of Education, but there is no single service with the designated overall responsibility for coordinating assessments. This leads to confusion amongst parents and primary health care providers about what to do when a child is identified as showing some autistic features. The recommended pathway leading to the assessment of a young child, older child or adolescent with suspected ASD is summarised in four steps:

I. Developmental surveillance

2. Identification of developmental concerns and appropriate referral

3. Appropriate referral and developmental service coordination

4. Multidisciplinary assessment (Ministry of Health and Education, 2016). 
The process is complex and can take many years for some. This can be debilitating as it prevents some families from accessing resources needed to learn and participate in school and to socialise. Often, if a child does not have the resources they need before the beginning school at the age of five, their learning is impacted and they fall behind their peers (Personal communication, February 21, 2020).

\section{SWOT and Needs Analysis}

Following the primary and secondary data collection and literature review, a strengths, weakness, opportunities and threats (SWOT), and needs analysis of children with Autism was completed to help the learners to identify what health promotion messages would be useful for families with children with ASD and for professionals

It is important to note however, that as with Autism and any disability, the way it impacts on individuals varies greatly. Due to Autism being a spectrum disorder, the strengths, weaknesses, opportunities and threats listed above do not fit or are relevant to every child with Autism or a disability. Instead, what is listed above is what may be relevant for children with disabilities.

The learners then discussed what needs we believe would be important to address for the ASD community, with the focus being on children and their families. Two of the needs that were identified were social isolation and the lack of resources available for families.

\section{Social Isolation}

Social isolation was a predominant theme expressed by parents with Autistic children. The challenges for children and families face in the community are about people not understanding how their child communicates and how they should be approached. The Education Act states disabled children have a right to education in all schools, however many families find there is a definite discouragement or hesitation to take on children with special needs into many schools. Parents say this is due to a lack of understanding about ASD.

The learners aimed to create a resource to help inform teachers and parents, about the condition to reduce social isolation. They wanted to create something to help 'normalise' Autistic children in all aspects of society so that they and their families feel welcome and comfortable in society rather than isolated. They considered that by educating adults about ASD, that they in turn will educate their children. The learners wanted to create more inclusiveness in schools and peers of children with ASD.

\section{Lack of Information and Resources}

Lack of resources was the second problem the learners identified and believed they could make a difference in. The learners highlighted this as a need after realising how little health professionals and the public know about the resources available for Autistic children and their families. While in the community collecting primary data for this project, they interviewed a variety of people, some were health professionals, parents, or people working within disability services and support groups. One major concern they noticed was that many of these people did not know what services were available for children with ASD. They felt that the lack of information was a barrier to people accessing services. They wanted to create a resource for health professionals, to inform them and give to their clients who have a child recently diagnosed with ASD. 


\section{PART 3: RESOURCES}

Following discussions with external primary resources and completing a literature review, the learners decided that the two gaps in Autistic community were social isolation and discrimination towards Autistic children, and the lack of information and resources available to this community. They created two resources for each need. Social isolation and discrimination towards autistic children are seen throughout the school system and the primary resources suggested that when teachers and adults model negative attitude towards autistic children, peers reciprocate the same attitude. There is also a lack of resources and support groups within this community, so the learners created resources to enable finding information easier and more accessible.

\section{Resource One}

The following resource aims to help promote a local playgroup targeting children with Autism (Figure 3).

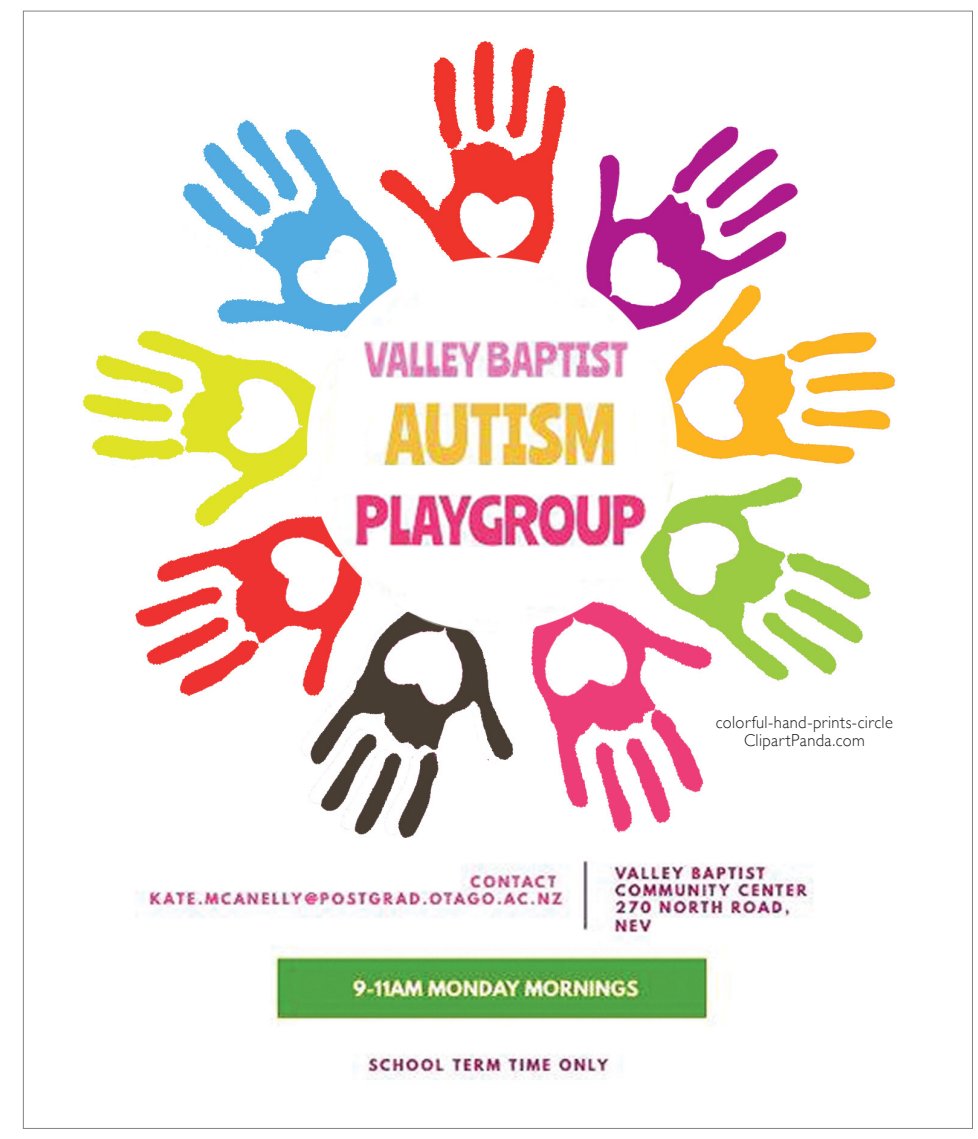

Figure 3. Pamphlet to promote local playgroup.

Source: Authors. 


\section{Resource Two}

The learners recognised the need for a resource listing all the services in Dunedin available for children with Autism and developed a poster. They incorporated artwork from children diagnosed with Autism, by using two different outlines of children's heads for them to draw inside to reiterate that all children with Autism are different. The artwork in Figure 4 has been included on the back of the poster, while the artwork in Figure 5 is on the front side of a pamphlet the students also developed. Both children were very excited to have their artwork on the resources.

Figure 4.

Back of poster listing resources on ASD in the Dunedin area. Source: Rachel Coombe.

Figure 5.

Front side of pamphlet. Source: Rachel Coombe.

\section{AUTISM}
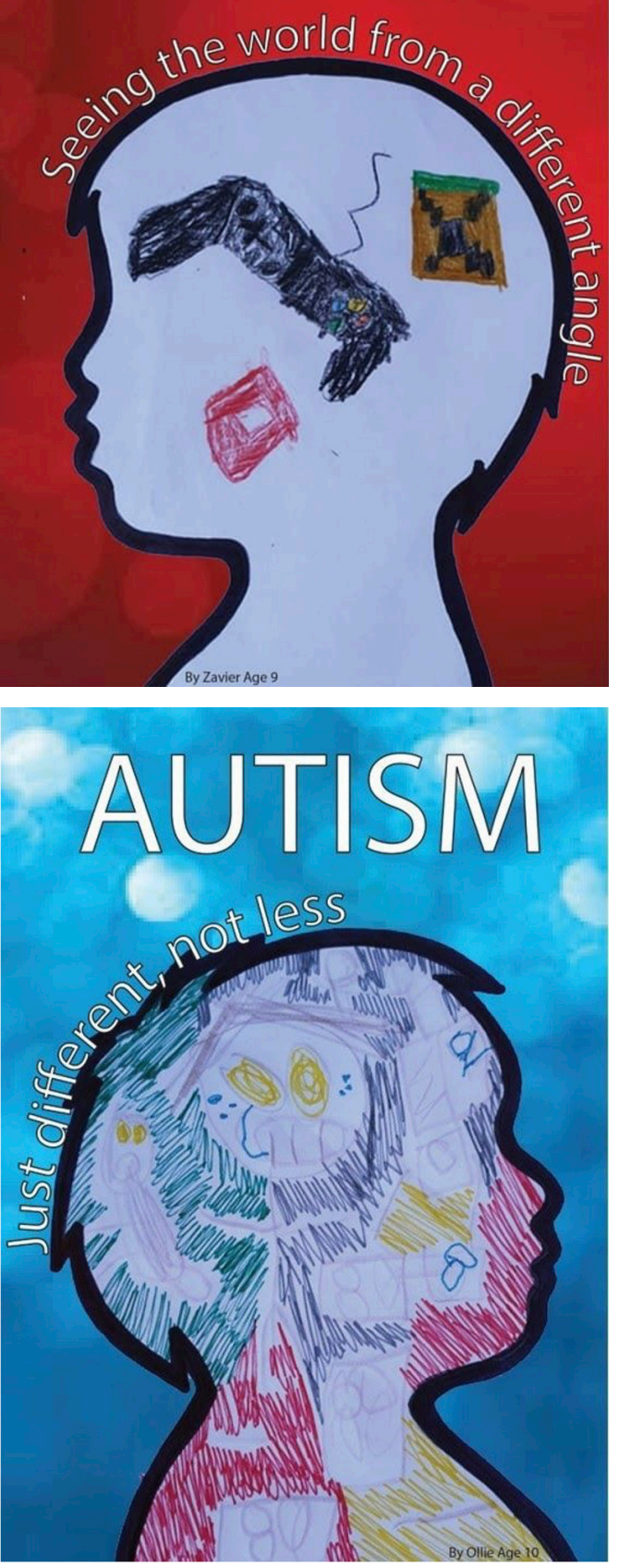


\section{Resource Three}

The third resource is a selection of six sticker designs promoting World Autism day awareness. Sadly, due to COVID-19 this was not able to be distributed to the Autistic Society for use on World Autism Day in 2020, but it is hoped that they will be used in the future.

\section{CONCLUSION}

Disabilities in different forms is a significant issue for New Zealand health, education, and social services, with 24 percent of all New Zealanders identifying as having a disability (Statistics New Zealand, 2013). Disabilities in children are different compared with those if adults, with 4 percent of children identified as having a psychological and learning disability (Statistics New Zealand, 2013). One of these disabilities is ASD, which is a lifelong is a neurodevelopmental condition that affects how people perceive the world, how they think and behave, as well as how they communicate and interact with others (Ministries of Health and Education, 2016).

The learners worked with the ASD Society, parents with children diagnosed with ASD, and health and education agencies, who identified significant difficulties and barriers that children with ASD and their families struggle with. These barriers are social isolation, lack of knowledge of available resources, and the lengthy diagnostic process are. The learners created a set of two resources that aim to try to reduce the barriers of social isolation and lack of knowledge of available resources. The third resource was stickers aiming to distribute on World Autism Day, however due to Covid-19 the learners were unable to distribute these.

Correspondence to: Laurie Mahoney. Email, Laurie.Mahoney@op.ac.nz

\section{REFERENCES}

Altogether Autism. (2020). Strengths and abilities in autism. Retrieved from https://www.altogetherautism.org.nz/strengths-andabilities-in-autism/

American Psychiatric Association. (2013). Diagnostic and statistical manual of mental disorders. (5th ed.). Retrieved from https:// www.psychiatry.org/psychiatrists/practice/dsm

Anderson, E., \& McFarlane, J. (2008). Community as partner: Theory and practice in nursing (6th ed.). Philadelphia, PA: Lippincott, Williams \& Wilkins.

Health Navigator. (2020). Retrieved from https://www.healthnavigator.org.nz/

Lindsay, S., \& McPherson, A. C. (2011). Strategies for improving disability awareness and social inclusion of children and young people with cerebral palsy. Child: Care, Health and Development, 38(6), 809-816. doi: 10.1 III/j.1365-2214.2011.01308.x

Milestones Day School and Transitions Programme. (2020). What does it mean to be "on the spectrum". Retrieved from https:// advancingmilestones.com/news/what-does-it-mean-to-be-on-the-spectrum/

Ministry of Education. (2020). The physical disability service. Retrieved from https://www.education.govt.nz/school/studentsupport/special-education/the-physical-dis ability-service/

Ministry of Health. (2015). Disability support services strategic plan 2014 to 2018. Wellington: Author.

Ministry of Health. (2016). New Zealand autism spectrum disorder guideline. Retrieved from https://www.health.govt.nz/ publication/new-zealand-autism-spectrum-disorder-guideline

Ministry of Health. (2018). Whāia Te Ao Mārama 2018 to 2022: The Māori disability action plan. Wellington: Author.

National Autistic Society. (2016). Autism. Retrieved from https://www.autism.org.uk/about/what-is/asd.aspx

Office for Disability Issues. (2016). New Zealand disability strategy 2016-2026. Retrieved from https://www.odi.govt.nz/nzdisability-strategy/about-the-strategy/new-zealand-disability-st rategy-2016-2026/ 
Plunket. (2020). Children with special needs. Retrieved from, https://www.plunket.org.nz/your-child/welcome-to-parenting/ parenting/children-with-special-needs/

Ross, J., Crawley, J., \& Mahoney, L. (2017). Sustainable community development: Student nurses making a difference. Scope: Contemporary Research Topics: Learning \& Teaching, 4, 8-17.

Statistics New Zealand. (2013). Table 2.01, Disability rate by age group, sex and ethnic group. Retrieved from https://www.stats. govt.nz/information-releases/disability-survey-2013

Statistics New Zealand. (2013). Table 7.01, Single/Multiple impairments for disabled people (percentage) by age group, sex and selected ethnic group. Disability Survey 2013 All Tables. Retrieved from https://www.stats.govt.nz/information-releases/ disability-survey-2013

Statistics New Zealand. (2014). Disability survey: 2013. Retrieved from https://www.stats.govt.nz/information-releases/disabilitysurvey-2013.

The National Autistic Society. (20I8). Common issues and challenges facing children on the autism spectrum. Retrieved from http://

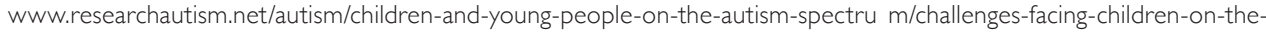
autism-spectrum

Very Well Health. (2019, Nov 19). What's the difference between high and low functioning autism? Retrieved from https://www. verywellhealth.com/high-and-low-functioning-autism-260599

Zuckerman, K., Lindly, O., \& Chavez, A. (2017). Timeliness of autism spectrum disorder diagnosis and use of services among U.S. elementary school-aged children. Psychiatric Services, 68(I), 33-40. doi: 10.1 176/appi.ps.201500549 